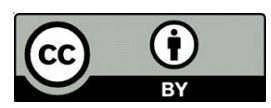

UDC 811.111'42

LBC 81.432.1-51
Submitted: 05.03.2021

Accepted: 30.08 .2021

\title{
ENGLISH DISCOURSE OF IMMIGRATION IN THE ASPECT OF CORPUS LINGUISTICS ${ }^{1}$
}

\author{
Marina S. Matytcina \\ Lipetsk State Technical University, Lipetsk, Russia \\ Tatiana Grigoryanova \\ University of Economics in Bratislava, Bratislava, Slovakia
}

\begin{abstract}
Based on data from the linguistic corpus News on the Web, the article examines the media discourse of immigration in the British and American media in the period from 2018 to 2020. Considering the linguistic facts from the standpoint of discursive linguistics and corpus analysis, the authors argue that the identification and quantification of collocations in which semantically the main component is represented by the words from the search query: immigrants and asylum seekers. Their ranking by degree of stability, as well as identification of the most common L1 collocates objectify information about the features of the English discourse of immigration. It was found out that in all types of the studied media, the most frequent collocations of the noun immigrant are with the adjectives illegal and undocumented, T. Grigoryanova notes they directly indicate illegal immigration as a serious social problem; the L1 frequency collocates of the asylum seeker search query unit are American and failed, M. Matytcina concludes that they actualize the significance of the immigration problem for the entire world community and contribute to the formation of anti-immigrant sentiment. In fixed collocations, according to T. Grigoryanova, they are replaced by the words other, central, new. The results of the analysis made it possible to conclude that the English discourse of immigration contains a protest against immigrants and asylum seekers, reflects the fear and anxiety of society about the consequences of increase in their number for the indigenous population.
\end{abstract}

Key words: corpus linguistics, corpus analysis, collocate, L1 collocate, discourse.

Citation. Matytcina M.S., Grigoryanova T. English Discourse of Immigration in the Aspect of Corpus Linguistics. Vestnik Volgogradskogo gosudarstvennogo universiteta. Seriya 2. Yazykoznanie [Science Journal of Volgograd State University. Linguistics], 2021, vol. 20, no. 6, pp. 29-41. (in Russian). DOI: https://doi.org/ 10.15688/jvolsu2.2021.6.3

УДК $811.111^{\prime} 42$

ББК $81.432 .1-51$
Дата поступления статьи: 05.03.2021 Дата принятия статьи: 30.08.2021

\section{АНГЛОЯЗЫЧНЫЙ ДИСКУРС ИММИГРАЦИИ В АСПЕКТЕ КОРПУСНОЙ ЛИНГВИСТИКИ ${ }^{1}$}

\author{
Марина Станиславовна Матыцина \\ Липецкий государственный технический университет, г. Липецк, Россия \\ Татьяна Григорянова \\ Экономический университет в Братиславе, г. Братислава, Словакия
}

Аннотация. В статье на основе данных лингвистического корпуса News on the Web исследуется медийный дискурс иммиграции в британских и американских СМИ в период с 2018 по 2020 год. Рассматривая языковые факты с позиций дискурсивной лингвистики и корпусного анализа, авторы утверждают, что выявление и количественная оценка коллокаций, в которых семантически главным компонентом выступают слова поискового запроса immigrants и asylum seekers, их ранжирование по степени устойчивости, а также опреде- 
ление наиболее распространенных L1 коллокатов объективируют информацию об особенностях англоязычного дискурса иммиграции. Установлено, что во всех типах изучаемых СМИ наиболее частотны коллокации существительного immigrant с прилагательными illegal и undocumented, прямо указывающие на нелегальную иммиграцию как серьезную социальную проблему (Т. Григорянова). Обнаружено, что частотными L1 коллокатами единицы поискового запроса asylum seeker являются American и failed, актуализирующие значимость проблемы иммиграции для всего мирового сообщества и способствующие формированию антииммигрантского настроения (М.С. Матыцина); в устойчивых коллокациях они заменяются словами other, central, new (Т. Григорянова). Результаты проведенного анализа позволили сделать выводы о том, что англоязычный дискурс иммиграции содержит протест против иммигрантов и лиц, ищущих убежища, отражает страх, тревогу социума по поводу того, чем увеличение их количества может обернуться для коренного населения.

Ключевые слова: корпусная лингвистика, корпусный анализ, коллокация, L1 коллокат, дискурс.

Цитирование. Матыцина М. С., Григорянова Т. Англоязычный дискурс иммиграции в аспекте корпусной лингвистики // Вестник Волгоградского государственного университета. Серия 2, Языкознание. - 2021. T. 20, № 6. - C. 29-41. - DOI: https://doi.org/10.15688/jvolsu2.2021.6.3

\section{Введение}

В настоящее время в отечественной и зарубежной науке увеличивается количество исследований конкретных и повторяющихся дискурсивных практик с использованием методов корпусного анализа. По мере проникновения современных информационных и коммуникационных технологий во все сферы науки, и в частности в филологию, возрастает востребованность лингвистических корпусов текстов при изучении различных аспектов языка. Корпусная лингвистика тесно связана с дискурсивной лингвистикой. В фокусе внимания лингвистики дискурса находится выявление средств интертекстуальности и интердискурсивности, а корпусная лингвистика занимается исследованием роли единиц языка в конструировании социальной реальности на основе максимального соответствия характеристик выборки характеристикам дискурса и, таким образом, позволяет усилить объективность доказательной базы. Дискурсивный анализ ориентирован на установление интертекстуальных и интердискурсивных связей между высказываниями, различными жанрами, текстами и типами дискурса, объясняющих актуализацию семиотических образований в тех или иных текстовых и дискурсивных пространствах. Корпусный анализ является количественным методом. Его использование связано с проблемой доказательства существования определенного явления в языке. Однако «быть в корпусе» не отождествляется с «быть в языке». В корпусе могут не получить своего отражения некоторые существующие языковые явления, при этом их отсутствие в корпусе может расцениваться как значимое, что приводит к ошибочным выводам.

Цель настоящего исследования заключается в определении специфики англоязычного дискурса иммиграции посредством объединения методологического инструментария дискурсивного анализа и корпусной лингвистики. Мы предполагаем, что выбранная методологическая основа обеспечит достижение объективности, установление точных эмпирических данных. В контексте гипотезы проводимой научной работы сообщения в СМИ рассматриваются как дискурсивные практики, отражающие особенности репрезентации иммигрантов и просителей убежища в англоязычном медиадискурсе, а также имплицитно выраженные установки и скрытые эффекты воздействия дискурса иммиграции на систему общественных отношений.

\section{Материал и методы}

Корпусный анализ в качестве методологической базы для изучения медийного дискурса иммиграции был выбран неслучайно. Во-первых, он выступает эффективным методом установления точных статистических данных, поскольку применение квантитативных методов для решения лингвистических задач позволяет собрать и обработать большее количество данных для изучения качественного состава словаря, получить объективную информацию о частотности языковых единиц, степени связности частей словосочетания и семантической просодии. Квантита- 
тивное исследование дискурса представляет собой надежный, контролируемый, ориентированный на результат обобщенный способ анализа целого ряда языковых явлений. Во-вторых, мы, вслед за П. Бейкером, считаем, что использование современных информационных технологий позволяет устранить возможность вмешательства человеческого фактора при проведении исследований, когда данные анализируются выборочно с целью подтверждения тех или иных гипотез. Это ставит под сомнение достоверность полученных ранее данных и объективность проведенного исследователем лингвистического анализа [Baker, 2006, p. 96]. В-третьих, построение матриц, отражающих встречаемость стандартной и нестандартной лексики и структур, по мнению П. Бейкера, облегчает поиск мотивационной базы тех позиций, установок, целей и интересов медиаэлиты, которые определяют дискурс как властный ресурс [Baker, 2006, p. 96].

Применение корпусного анализа позволяет дополнить семантический и прагматический анализ высказываний, а также выявить наиболее рекуррентные лингвистические механизмы реализации структур дискурса и дискурсивных стратегий, использованных для репрезентации иммигрантов и лиц, ищущих убежища [Gabrielatos, Baker, 2006; 2008; Baker et al., 2008; KhosraviNik, 2009].

В статье предметом анализа стали особенности конструирования в медиадискурсе образа иммигранта и лиц, ищущих убежища, поскольку, несмотря на широкое распространение подобных исследований, некоторые вопросы в области изучения специфики формирования такого дискурса в СМИ рассматриваются, на наш взгляд, односторонне.

Материалом для изучения послужили данные корпуса News on the Web - новостные статьи британских и американских качественных периодических изданий, бульварных изданий, таблоидов и информационных агентств, опубликованные в период с 2018 по 2020 год. Выбранные информационные источники разделены на категории, предложенные некоммерческой независимой организацией Великобритании «Audit Bureau of Circulations» (АВС; «Бюро аудита тиражей»), определяющей стандарты для измерения медиабрендов печатных публикаций и цифровых каналов:
1) британские и американские качественные периодические издания (The Times, The Sunday Times, The Daily Telegraph, The Guardian, The New York Times, The Wall Street Journal, The Washington Post, The Washington Times); 2) бульварные издания (The Daily Mail, The Sunday Express, The Daily Express); 3) таблоиды (The Daily Mirror, The Sun, The New York Post); 4) информационные агентства (CNN, BBC News, FOX News, ABC News, Reuters).

Kорпус News on the Web ежемесячно увеличивается приблизительно на 180-200 миллионов слов из 300000 новых статей, что составляет 2 миллиарда слов ежегодно. Материал исследования отбирался посредством поискового запроса: immigrants и asylum seekers («иммигранты», «просители убежища»). Объем сведений, полученный из выбранных источников, является, на наш взгляд, достаточным для всестороннего понимания и объяснения дискурсивных характеристик образа иммигрантов и лиц, ищущих убежища, на страницах изданий и информационных агентств. Как и ожидалось, количество статей, затрагивающих тему иммиграции, опубликованных в СМИ в период с 2018 по 2020 г. без ограничений по типу, размеру и идеологической позиции, было внушительным - около 100 тысяч.

Использование широких критериев отбора позволило достичь научной объективности в отношении процедуры подбора материала. Применение электронного корпуса дало возможность выявить и количественно оценить часто повторяющиеся устойчивые словосочетания, в которых семантически главным компонентом выступают слова поискового запроса. Кроме того, по сравнению с традиционной лингвистикой, которая имеет описательный и интроспективный характер, полученные на основе корпуса количественные данные не являются субъективной интерпретацией агентами коммуникации ситуативной модели.

\section{Результаты и обсуждение}

Для исследования медийного дискурса иммиграции мы поставили ряд задач. Во-первых, определить коллокации, в которых семантически главным компонентом выступали бы лексические единицы immigrants и asylum seekers, и ранжировать выявленные коллока- 
ции по степени устойчивости. Во-вторых, найти самые распространенные L1 коллокаты исследуемых слов immigrants и asylum seekers.

В современной лингвистике существуют различные определения понятия «коллокация». Большинство из них строится на феномене повторяющегося сочетания двух или более слов, совместно появляющихся в тексте [Sinclair, 1991; Stubbs, 1995]. Согласно У. Фаулеру, термин collocate («коллокация») в лингвистическом аспекте впервые был употреблен Дж.Р. Фертом для обозначения совместной встречаемости отдельных слов. В работе «Modern English Usage» У. Фаулер приводит примеры часто встречаемых сочетаний отдельных слов и определяет эту связность как неотъемлемую часть организации языка (см.: [Burchfield, 1996, p. 158]). О.С. Ахманова в «Словаре лингвистических терминов» приводит следующее определение коллокаций, принимаемое авторами настоящей работы: «коллокация - это лексикофразеологически обусловленная сочетаемость слов в речи для реализации их полисемии» [Axманова, 1966, с. 194]. Изучение паттернов коллокаций в больших массивах текстов, по мнению П. Бакера, способствует пониманию значений слов, которые их образуют, взаимообусловленности элементов словосочетания, что трудно установить из анализа отдельно взятого текста [Baker, 2006, p. 96]. Статистические исследования показывают не только частоту встречаемости слов в корпусе, но и направление изменений лексических значений слов при устойчивости словосочетания. Это позволяет исследователям провести анализ извлеченной из корпуса информации как в квалитативном, так и квантитативном ракурсе и оценить силу притяжения слов (см., например: [Hunston, 2007; McEnery, Hardie, 2011]).

Обширный лингвистический материал корпуса показывает, что если семантически главным компонентом в словосочетании выступает лексическая единица immigrants, то вспомогательным компонентом словосочетания, или коллокатом, является слово, которое чаще других сочетается с главным компонентом словосочетания в данном корпусе. В этом случае анализируются релевантные единицы, находящиеся на заданном расстоянии от исследуемого слова. В нашем исследовании это первые пять слов (a five-word window) без учета служебных единиц, стоящие либо в препозиции, либо в постпозиции к главному компоненту словосочетания. Поиск коллокаций с таким количеством слов, согласно исследованиям других ученых, представляется оптимальным, поскольку большее количество может привести к языковым искажениям (см., например: [Baker, Gabrielatos, McEnery, 2013]). Типичные повторяющиеся сочетания со словом immigrants, выделенные из корпуса, дают дополнительное представление о практике реального использования этих моделей в языке.

Результаты сочетаемости слова immigrants в исследуемом корпусе представлены в таблице 1 , согласно которой наиболее частотной является коллокация illegal immigrants - она встречается в $42 \%$ статей.

Второй этап анализа заключался в поиске L1 коллокатов исследуемого слова. Слова в указанном диапазоне являются коллокатами целевого (исследуемого) слова, которое на рисунке 1 обозначено как target («цель»). На рисунке показано расположение коллока-

Таблица 1. Количественная характеристика коллокатов слова immigrants, 2018-2020 гг.

\section{Table 1. Quantitative characteristics of collocates of the word immigrants, 2018-2020}

\begin{tabular}{|c|c|c|c|}
\hline Коллокат & Перевод & Количество & Доля, \% \\
\hline illegal & нелегальные & 14770 & 42 \\
\hline undocumented & не имеющие документов & 8992 & 26 \\
\hline new & новые & 2338 & 7 \\
\hline young & молодые & 1739 & 5 \\
\hline Mexican & мексиканские & 1364 & 4 \\
\hline Chinese & китайские & 1353 & 4 \\
\hline Indian & индийские & 1050 & 3 \\
\hline unauthorized & неразрешенные & 1043 & 3 \\
\hline African & африканские & 998 & 3 \\
\hline other & другие & 986 & 3 \\
\hline & Bcezo & 34633 & 100 \\
\hline
\end{tabular}


М.С. Матыциина, Т. Григорянова. Англоязычный дискурс иммиграции в аспекте корпусной лингвистики

тов по обеим сторонам исследуемого слова. Лексическая единица, стоящая непосредственно перед исследуемым словом, определяется как L1 коллокат. Анализ данных корпуса показывает, что L1 коллокат является определяющим словом, выраженным разными частями речи и поясняющим признаки исследуемого слова. L1 коллокаты представляют собой речевые паттерны и указывают на закономерности употребления слов, используемых для описания иммигрантов и просителей убежища, в то время как L2-L5 коллокаты - это лексические единицы, составляющие коллокацию с целевым словом, но встречающиеся в такой паре реже.

Наиболее частотным L1 коллокатом существительного immigrants является прилагательное illegal (рис. 2).

Оценочное прилагательное illegal в качестве L1 коллоката существительного immigrants намного чаще используется в качественных изданиях и публикациях информационных агентств, чем в бульварных изданиях и таблоидах (рис. 3).

\begin{tabular}{|l|l|l|l|l|l|l|l|l|l|l|}
\hline L5 & L4 & L3 & L2 & L1 & TARGET & R1 & R2 & R3 & R4 & R5 \\
\hline
\end{tabular}

Рис. 1. Расположение коллокатов по отношению к исследуемому слову

Fig. 1. Location of collocates in relation to the word under study

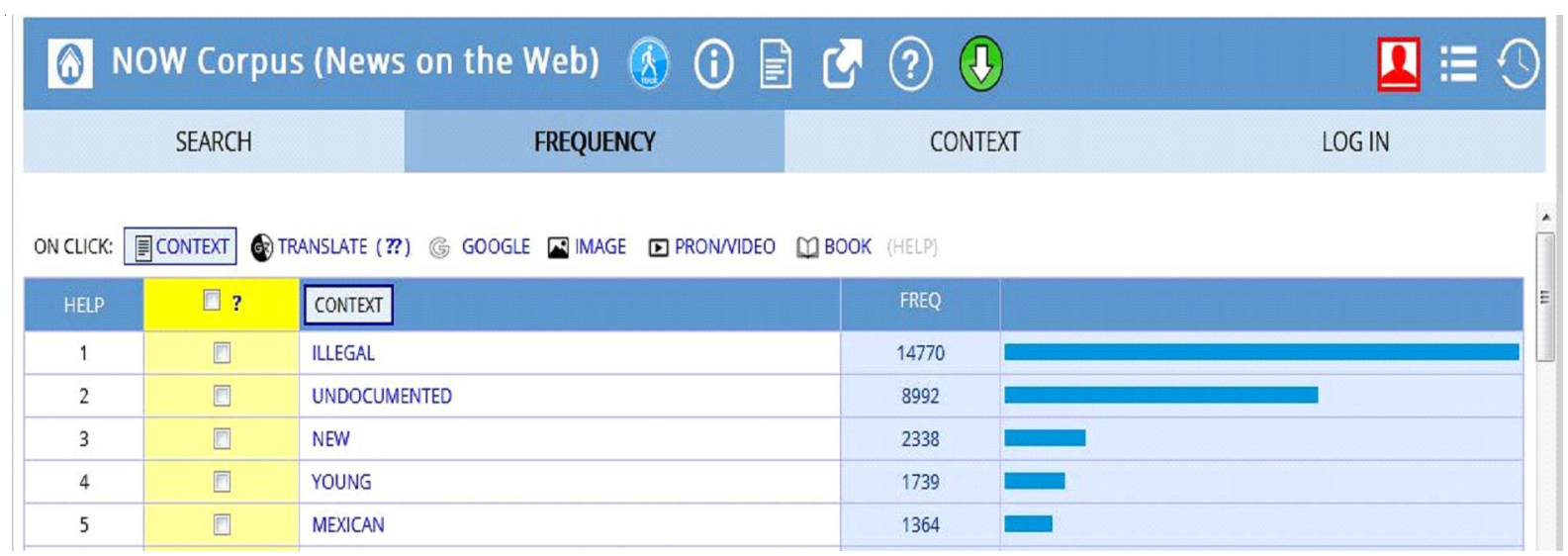

Рис. 2. C-collocates существительного immigrants

Fig. 2. C-collocates of the noun immigrants

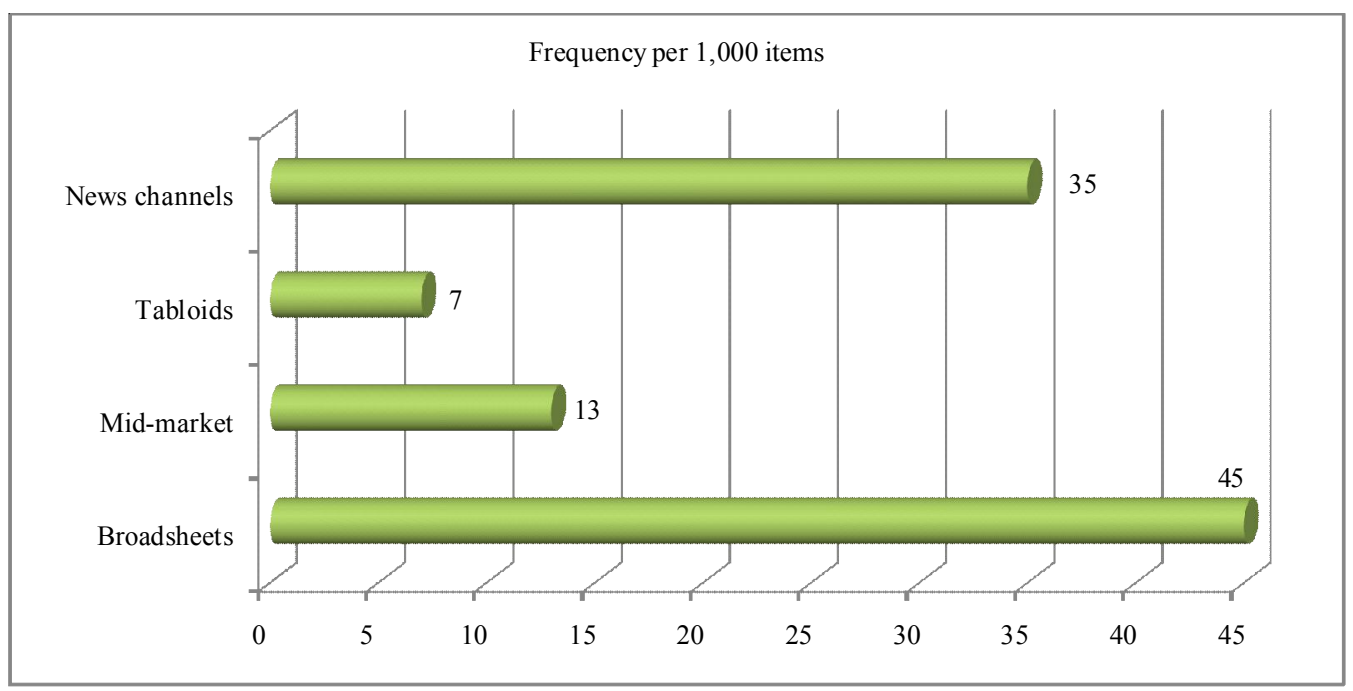

Рис. 3. Illegal как L1 коллокат существительного immigrants в изданиях разных типов

Fig. 3. Illegal as a Top L1 Collocate of the noun immigrants by publication type 
Как видим, в 4,5 \% статей качественной прессы и 3,5 \% сообщений информационных агентств предпочтение отдается фразе illegal immigrants, а бульварные издания и таблоиды характеризуют иммигрантов как нелегальных в 1,3\% и 0,7 \% соответственно. Иными словами, все типы изданий подчеркивают нарушение иммигрантами законов, определяют этот круг лиц как угрозу европейскому населению.

Слово illegal в качестве L1 коллоката становится ключевым для описания преступных действий со стороны иммигрантов и служит ярким примером использования властными структурами средств массовой информации для воспроизводства стереотипов, связанных с этой социальной группой в сознании граждан страны. Формируемые в результате такого воздействия индивидуальные ментальные репрезентации дискурса соотносят структуры дискурса с коммуникативными ситуациями, отражая то, как участник коммуникативного события интерпретирует происходящее действие, и одновременно оказывая воздействие на существующие социальные отношения. Описывая иммигрантов как нелегалов, англоязычная пресса и информагентства выстраивают особую концепцию иммиграции, которая, во-первых, подчеркивает проблему правового статуса и, во-вторых, изображает иммигрантов как нарушителей закона. Очевидно, что СМИ модифицируют существующие социальные отношения в интересах лиц, определяющих политику, создавая и укрепляя стереотипы в понимании того, что такое иммиграция и кто такие иммигранты. Социум убеждают в том, что существует серьезная проблема с обеспечением безопасности, поэтому необходимо установление жесткого контроля. Таким образом, и для общественности, и для СМИ незаконность отождествляется с иммиграцией. Обращает на себя внимание тот факт, что издания устанавливают гипо-гиперонимические связи между словами immigrants и illegal, то есть иммигранты квалифицируются как нарушители законов, а их передвижение - как преступление, а не как вынужденная мера. Изложение информации посредством рекуррентной последовательности лексических единиц illegal immigrants в англоязыч- ных массмедиа является механизмом порождения нужных власти смыслов, влияющих на отношение коренного населения к иммигрантам.

Приведем некоторые примеры из корпуca, иллюстрирующие формирование и поддержание средствами массовой информации общественного мнения о нелегальных иммигрантах как проблеме:

(1) A total of 27 illegal immigrants and one boat skipper were detained during Ops Benteng while eight land vehicles were seized (Petaling, 2020);

(2) Macgregor has referred to immigrants to Europe as "Muslim invaders", advocated shooting illegal immigrants on the US border, and promoted a range of white nationalists conspiracy theories (Borger, 2020).

Другим L1-коллокатом, образующим высокоустойчивое сочетание с лексической единицей immigrants, является прилагательное undocumented. Иногда оно используется как альтернатива прилагательному illegal и в большинстве случаев употребляется в контексте обсуждения проблем иммиграции в США, а не Великобритании. Приоритетной темой изданий становится освещение дебатов по иммиграционной реформе, проводимой правительством США в отношении иностранцев, находящихся на территории страны без необходимых для этого документов:

(3) Padilla, graduated from the Massachusetts Institute of Technology with an engineering degree, says he became politically engaged in 1994 - as many Latinos did - when Californians passed Proposition 187 , the initiative aimed at cutting public spending on undocumented immigrants, including public schooling and nursing home care (Morain, 2020);

(4) As the mayor of reliably Democratic MiamiDade County in Florida, Carlos A. Gimenez, a Republican, six days after the inauguration in 2017 became the first big-city leader in the country to reverse the county's de facto status as a "sanctuary" for undocumented immigrants (Shear, 2020).

Следующим этапом анализа стало выявление устойчивых коллокаций, или «c-collocates», наиболее часто встречаемых слов, стоящих на расстоянии пяти слов в препозиции и постпозиции без учета служебных слов к слову immigrants (см. рис. 4). 


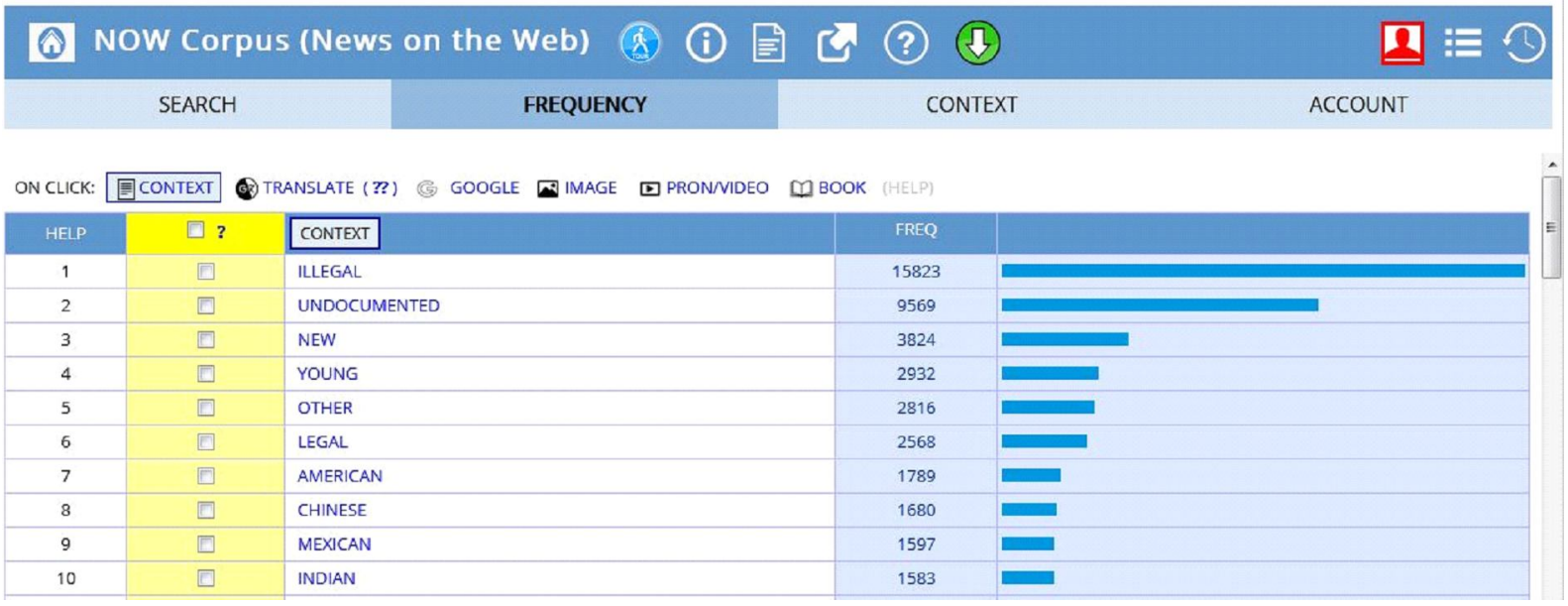

Рис. 4. Наиболее частотные c-collocates существительного immigrants

Fig. 4. Top c-collocates of the noun immigrants

Как показано на рисунке, слово illegal сохраняет наибольшую частотность во всех типах исследуемых изданий.

Количественная характеристика устойчивой коллокации лексической единицы immigrants с коллокатом illegal в разных типах источников приведена на рисунке 5.

Авторы публикаций в качественных СМИ характеризовали иммигрантов с помощью прилагательного illegal в 7,2 \% случаев. Для информационных агентств и бульварных изданий этот показатель равен 4,3 \% и 1,1\% соответственно, для таблоидов - 0,5\%.

Полученные данные формируют целостную картину современного этапа политической коммуникации, помогают лучше по- нять дискурсивные механизмы формирования отношения к иммигрантам, используемые разными изданиями. Все этапы анализа коллокаций дают четкое представление о тех речевых моделях, которые применяются англоязычными массмедиа для характеристики иммигрантов.

Исследователь из Массачусетского университета в Амхерсте С. Блиндер отмечает, что на страницах газет Великобритании и США отражаются продуцируемые властными структурами ментальные модели и в отношении просителей убежища, то есть лиц, уже покинувших свою страну, въехавших в другую страну и ходатайствующих в органах власти о предоставлении убежища [Blinder, 2015]. Согласно

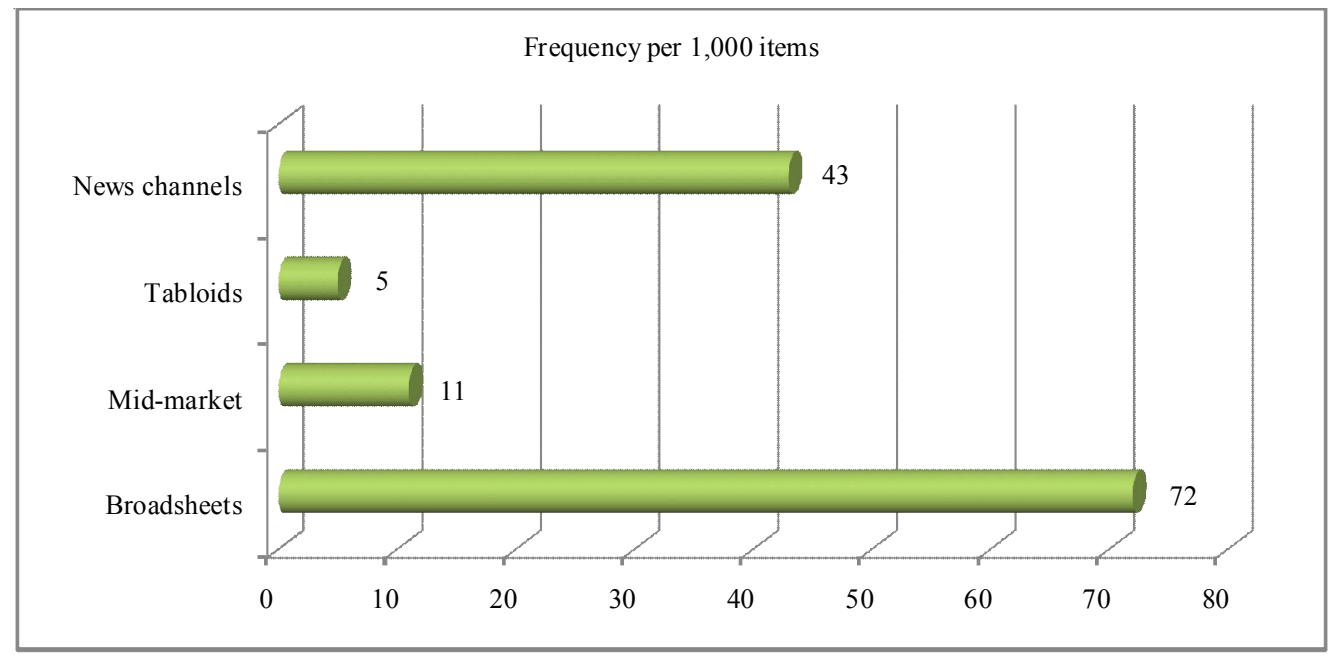

Pис. 5. Illegal как самый частотный с-collocate существительного immigrants в изданиях разных типов

Fig. 5. Illegal as a Top c-collocate of the noun immigrants by publication type 
Т.А. ван Дейку, «ментальные модели в эпизодической памяти управляют многими свойствами порождения и восприятия дискурса, речевыми актами, стилем, выбором лексических средств, форматом, риторикой, семантическими стратегиями и т. д.» [Дейк, 2015, c. 230]. Ментальные модели соотносят структуры дискурса с коммуникативными ситуациями, отражая то, как участник коммуникативного события интерпретирует происходящее действие. Результаты сочетаемости asylum seeker в исследуемом корпусе представлены в таблице 2.

В работе «Bad News for Refugees» исследователями университета Глазго поднимается проблема освещения в прессе вопросов, связанных с проявлением враждебности и неприязни к лицам, ищущим убежища [Philo, Briant, Donald, 2013]. Анализируя новостные сообщения, авторы рассматривают способы создания и поддержания стереотипов в отношении иммигрантов в сознании индивида, формирования дискурса, в рамках которого экономические мигранты, беженцы и лица, ищущие убежища, объединяются в одну «группу». Она становится предметом политических разногласий. Медиааналитики объясняют негативную реакцию коренного населения на вновь прибывших, описывая случаи мошенничества при получении пособий, краж на работе, уличной преступности, которые составляют содержательную основу новостных текстов, касающихся иммигрантов. В ходе исследования ученые выявляют различные семантические, прагматические и социально-политические стратегии формиро- вания антииммигрантских представлений, взглядов и установок в доминирующем дискурсе власти, используя такие формулировки, как bogus asylum seekers и illegal asylum seekers. Такие словосочетания бессмысленны с политической точки зрения, поскольку поиск убежища сам по себе не может быть нелегальным. Однако просители убежища, заявления и апелляции которых были отклонены, могут остаться в стране незаконно. Факты, установленные медиааналитиками из Глазго, находят подтверждение и в настоящем исследовании. Так, в качестве одного из наиболее частотных L1 коллокатов словосочетания asylum seeker в исследуемом корпусе выступает слово failed (см. рис. 6).

Наиболее частотным L1 коллокатом является прилагательное American. Это подтверждается и распределением статей с таким L1 коллокатом по публикациям изданий разных типов (см. рис. 7).

Данные диаграммы свидетельствуют о том, что вопрос об иммиграции для США стоит особенно остро. Словосочетание American asylum seekers использовано в 24,5 \% новостных статей информационных агентств и в $14 \%$ статей качественной прессы, в то время как в бульварных изданиях оно представлено лишь в 4 \% публикаций, а в таблоидах не употреблено вовсе. Приведем некоторые примеры из корпуса, иллюстрирующие, что просители убежища становятся все более серьезной проблемой в США, а для ее решения требуется ужесточение пограничного контроля и депортация незаконных иммигрантов:

\section{Таблица 2. Количественная характеристика L1 коллокатов сочетания asylum seekers,} 2018-2020 гг.

Table 2. Quantitative characteristics of $\mathrm{L} 1$ collocates of the word combination asylum seekers, 2018-2020

\begin{tabular}{|l|l|c|c|}
\hline \multicolumn{1}{|c|}{ L1 коллокат } & \multicolumn{1}{|c|}{ Перевод } & Количество & Доля, \% \\
\hline American & американские & 244 & 20 \\
\hline African & африканские & 186 & 16 \\
\hline failed & неудавшиеся & 159 & 13 \\
\hline other & другие & 126 & 10 \\
\hline Honduran & гондурасские & 103 & 9 \\
\hline rejected & которым отказано & 83 & 7 \\
\hline new & новые & 81 & 7 \\
\hline would-be & потенциальные & 73 & 6 \\
\hline vulnerable & незащищенные & 71 & 6 \\
\hline Iranian & иранские & 70 & 6 \\
\hline \multicolumn{2}{|c}{ Bсего } & 1196 & 100 \\
\hline
\end{tabular}




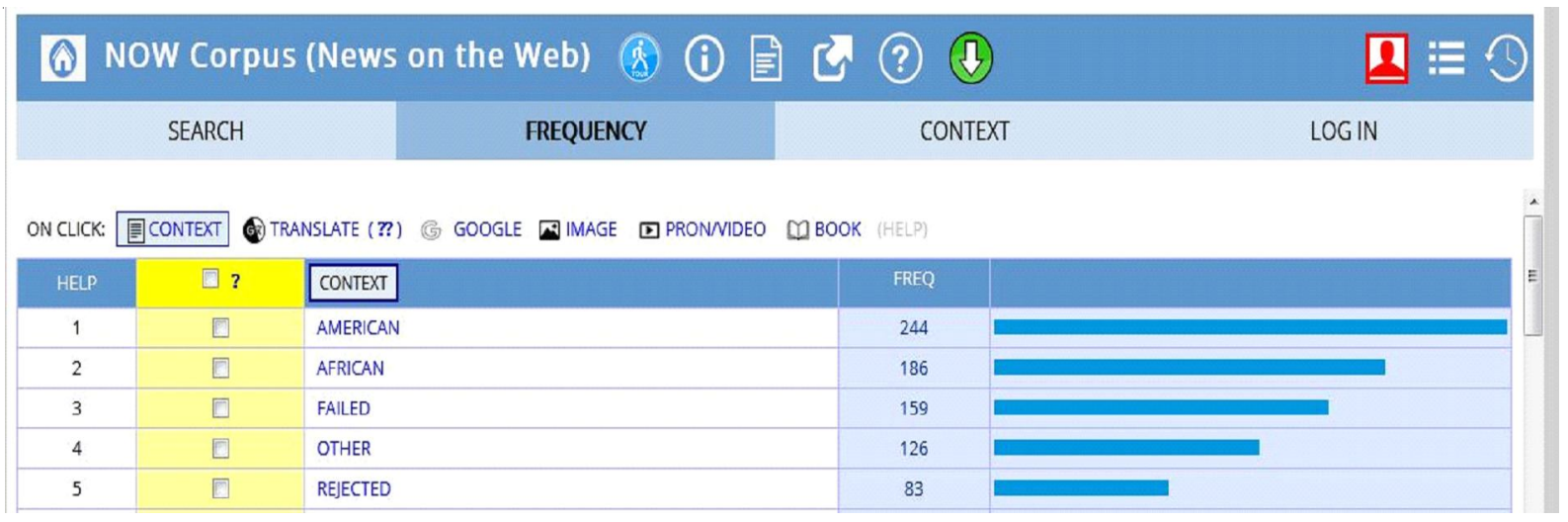

Рис. 6. Наиболее частотные L1 коллокаты сочетания asylum seekers

Fig. 6. Top L1 collocates of the word combination asylum seekers

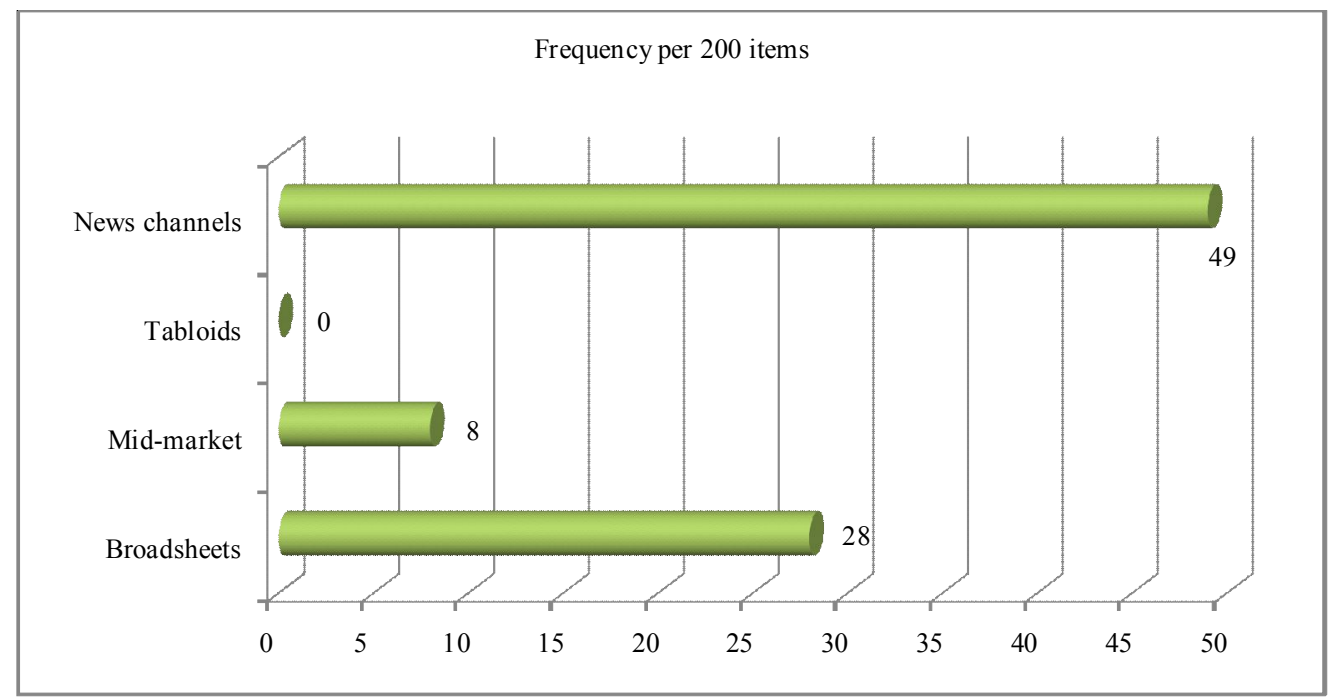

Рис. 7. American как L1 коллокат сочетания asylum seekers в изданиях разных типов

Fig. 7. American as a Top L1 Collocate of the word combination asylum seekers by Publication Type

(5) Central American asylum seekers detained in McAllen, Tex. on June 12 were sent to a processing centre for possible separation (Leonhardt, 2018);

(6) Central American asylum seekers wait for transport while being detained by US border patrol agents near the US-Mexico border in McAllen (Powell, 2018);

(7) The relocation seeks to disband the group of some 1,400 Central American asylum seekers and prevent potential mass attempts to rush for the border fence to cross to the U.S., as happened in Tijuana late last year (Montes, 2019).

Наиболее часто встречаемыми словам, стоящим на расстоянии пяти слов в препозиции и в постпозиции без учета служебных слов к asylum seekers, относятся other, central, new, American (см. рис. 8).
Слово other в качестве альтернативы лексическим единицам American и failed неодинаково частотно использовано в различных источниках (см. рис. 9).

Как свидетельствуют данные диаграммы, в публикациях информационных агентств лица, ищущие убежища, характеризовались посредством other в 22,8 \% статей, в качественных изданиях - в 14,6\%, в бульварных изданий - в 3,8 \%, а в таблоидах - лишь в 1 \% статей.

\section{Заключение}

Анализ данных, полученных в результате корпусного исследования целевого слова immigrants и словосочетания asylum seekers, позволяет определить следующие закономер- 


\section{ГЛАВНАЯ ТЕМА НОМЕРА}

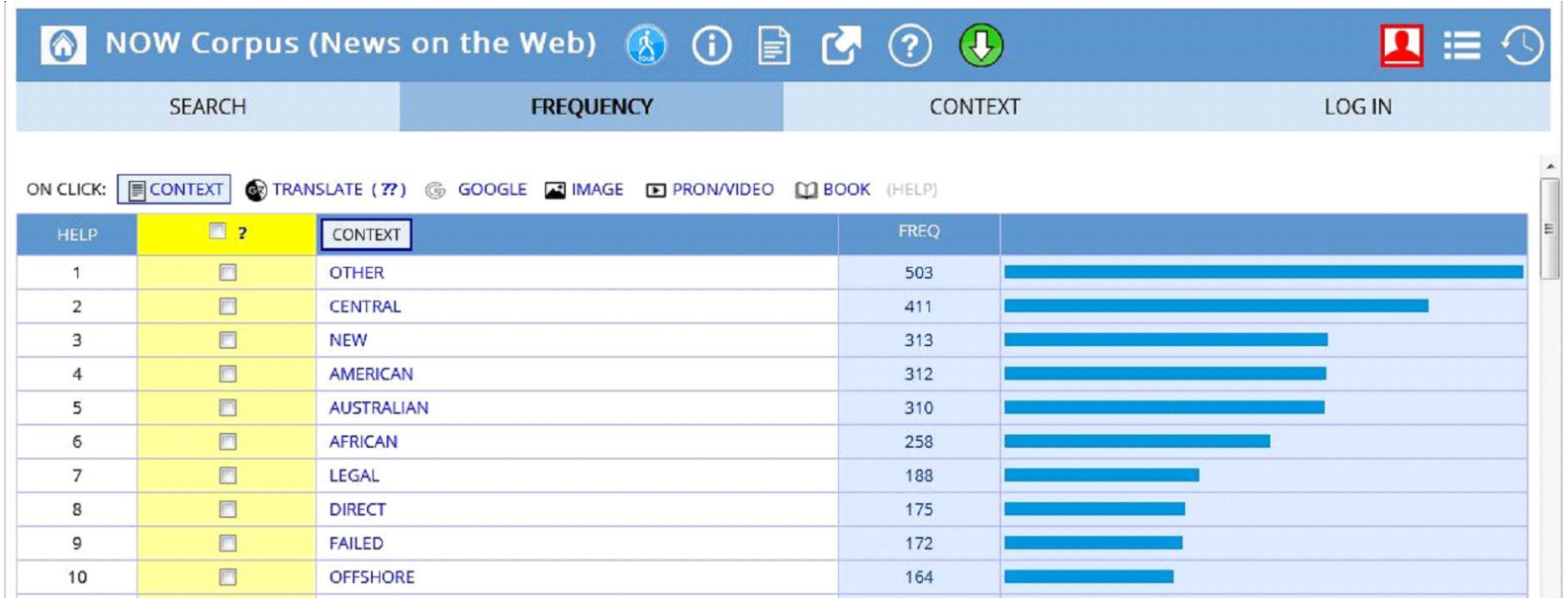

Рис. 8. Наиболее частотные с-collocates сочетания asylum seekers

Fig. 8. Top c-collocates of the word combination asylum seekers

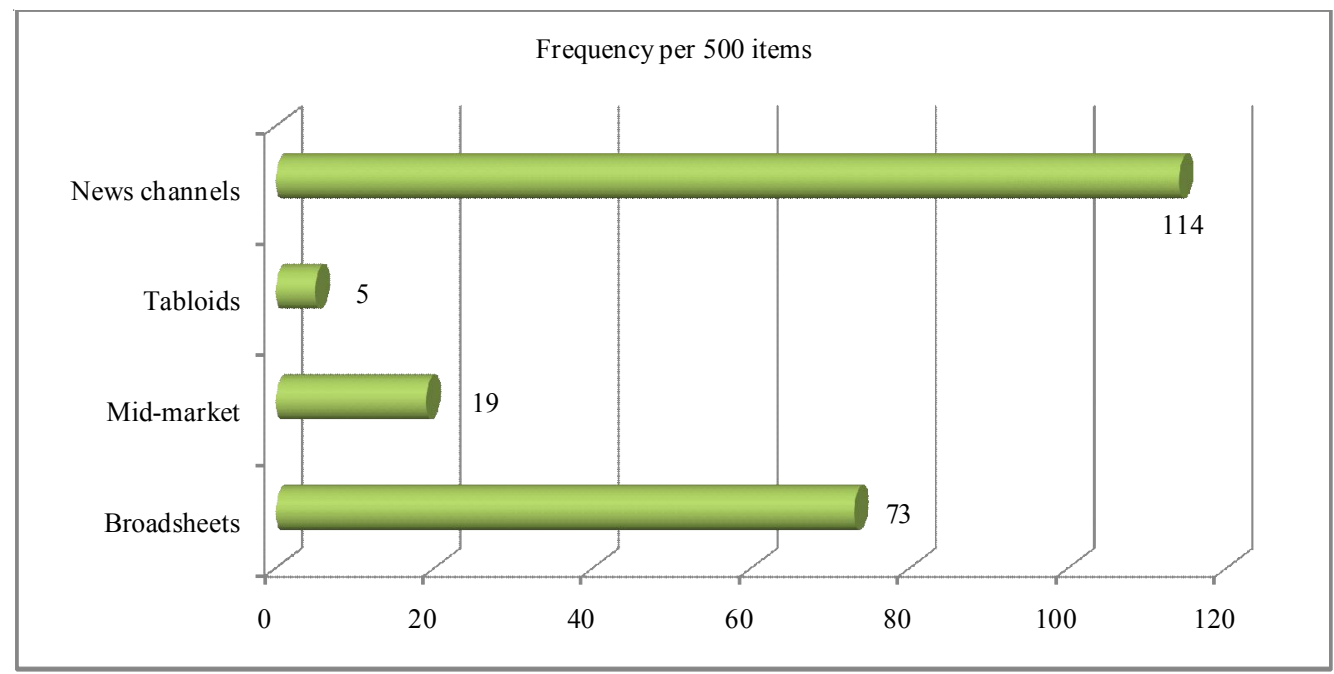

Рис. 9. Other как самый частотный с-collocate сочетания asylum seekers в изданиях разных типов

Fig. 9. Other as a Top c-collocate of the word combination asylum seekers by Publication Type

ности в использовании тех лексических единиц, которые участвуют в дискурсивном конструировании медийного образа иммигрантов и лиц, ищущих убежища. Наиболее употребительными являются сочетания слова immigrants с прилагательными illegal и undocumented, которые выступают также и L1 коллокатами лексической единицы immigrants. Это свидетельствует о том, что illegal и undocumented становятся ключевыми определениями в отношении требующих вмешательства правительства преступных действий со стороны иммигрантов. Прилагательное illegal coхраняет наибольшую частотность употребления с целевым словом immigrants и образует с данной лексической единицей устойчивую коллокацию в источниках исследуемого трехлетнего периода.

Как показывает данное исследование, самыми частотные L1 коллокатами сочетания asylum seekers являются слова American, African и failed. Частотность употребления словосочетания American asylum seeker доказывает то, что проблема иммиграции не рассматривается англоязычной прессой как исключительно национальная проблема какойлибо страны Европейского союза, а представляет собой часть общего социокультурного и языкового контекста всего мирового сообщества. Лексическая единица illegal сохраняет наибольшую частотность употребления с целевым словом immigrants и образует с ним 
устойчивое сочетание в источниках всех исследуемых типов, в то время как в устойчивых коллокациях со словосочетанием asylum seekers лидирующую позицию занимает слово other, что подтверждает сложность определения специфики англоязычного дискурса иммиграции.

Выявленные в результате анализа коллокации исследуемых лексических единиц свидетельствуют о том, что иммигранты и лица, ищущие убежища, изображаются как угроза европейской безопасности, порождающая чувство страха у читателей. На основе такой репрезентации дискурса авторами новостных публикаций делается следующий вывод: обществу необходимо осознать всю серьезность ситуации и принять безотлагательные меры в отношении регулирования иммиграционных потоков и порядка предоставления убежища на территории государств.

Исследование дискурсивных характеристик медийного образа иммигрантов и лиц, ищущих убежища, на основе корпусного анализа способствует созданию исчерпывающей статистической базы данных о лингвистическом наполнении дискурса об иммигрантах на страницах изданий и в сообщениях информационных агентств.

\section{ПРИМЕЧАНИЕ}

${ }^{1}$ Исследование выполнено при финансовой поддержке Министерства образования, науки, исследований и спорта Словацкой Республики в рамках научного проекта KEGA 018EU-4/2020 «Профессиональный русский язык и ИКТ в онлайн-среде».

The reported study was funded by Ministry of Education, Science, Research and Sports of the Slovak Republic, project number 018EU-4/2020 "Professional Russian language and ICT in online environment".

\section{СПИСОК ЛИТЕРАТУРЫ}

Ахманова О. С., 1966. Словарь лингвистических терминов. М. : Сов. энцикл. $606 \mathrm{c}$.

Дейк Т. А. ван, 2015. Дискурс и власть: репрезентация доминирования в языке и коммуникации. М. : УРСС : ЛИБРОКОМ. 352 c.

Baker P., 2006. Using Corpora in Discourse Analysis. L. : Bloomsbury Academic. 198 p.

Baker P., Gabrielatos C., McEnery T., 2013. Discourse Analysis and Media Attitudes: The Representation of Islam in the British Press. Cambridge : Cambridge University Press. 280 p.

Baker P., KhosraviNik M., Krzyzanowski M., McEnery T., Wodak R., 2008. A Useful Methodological Synergy? Combining Critical Discourse Analysis and Corpus Linguistics to Examine Discourses of Refugees and Asylum Seekers in the UK Press // Discourse \& Society. Vol. 19(3). P. 273-306. DOI: https://doi.org/10.1177/0957926508088962.

Blinder S., 2015. Imagined Immigration: The Impact of Different Meanings of 'Immigrants' in Public Opinion and Policy Debates in Britain // Political Studies. Vol. 63 (1). P. 80-100.

Hunston S., 2007. Semantic Prosody Revisited // International Journal of Corpus Linguistics. Vol. 12 (2). P. 249-268.

Gabrielatos C., Baker P., 2006. Representation of Refugees and Asylum Seekers in UK Newspapers: Towards a Corpus-Based Comparison of the Stance of Tabloids and Broadsheets // First International Conference: Critical Approaches to Discourse Analysis Across Disciplines (University of East Anglia, Norwich, UK, 2930 June 2006). URL: https://eprints.lancs.ac.uk/ $\mathrm{id} /$ eprint $/ 250$ (date of access: 01.03.2021).

Gabrielatos C., Baker P., 2008. Fleeing, Sneaking, Flooding. A Corpus Analysis of Discursive Constructions of Refugees and Asylum Seekers in the UK Press, 1996-2005 // Journal of English Linguistics. Vol. 36 (1). P. 5-38. DOI: https:// doi.org/10.1177/0075424207311247.

KhosraviNik M., 2009. The Representation of Refugees, Asylum Seekers and Immigrants in British News-Papers During the Balkan Conflict (1999) and the British General Election (2005) // Discourse \& Society. Vol. 20 (4). P. 477-498. DOI: https://doi.org/10.1177/0957926509104024.

McEnery T., Hardie A., 2011. Corpus Linguistics: Method, Theory and Practice. Cambridge : Cambridge University Press. 292 p.

Philo G., Briant E., Donald P., 2013. Bad News for Refugees. L. : Pluto Press. 224 p.

Sinclair J., 1991. Corpus, Concordance, Collocation. Oxford: Oxford University Press. 179 p.

Stubbs M., 1995. Collocations and Semantic Profiles: On the Cause of the Trouble with Quantitative Studies // Functions of Language. Vol. 2 (1). P. 2355. DOI: https://doi.org/10.1075/fol.2.1.03stu.

\section{ИСТОЧНИКИ}

Borger J. Downright Dangerous: Democrats' Alarm As Trump Stacks Pentagon with Loyalists. 2020. URL: https://www.msn.com/en-gb/news/world/ downright-dangerous-democrat-alarm-as- 
trump-stacks-pentagon-with-loyalists/arBB1aUsS2?fbclid=IwAR0BOfY8tolEcZnPO TiJK1RnBIjvchQpjAzd1_4XIITI7OSS5wokP48Lno (date of access: 01.03.2021).

Burchfield R.W. The NewFowler's Modern English Usage. $3^{\text {rd }}$ ed. Oxford: Clarendon Press, 1996. $864 \mathrm{p}$.

Corpus of News on the Web (NOW). URL: https:// www.english-corpora.org/now/.

Leonhardt D. Team Trump's 3 Bizarre Defenses of Child Separations. 2018. URL: https://www.nytimes.com/ 2018/06/18/opinion/trump-family-separationimmigrant-border.html (date of access: 01.03.2021).

Montes J. Mexican Authorities Relocate Hundreds of Migrants from Border City. 2019 URL: https:// www.wsj.com/articles/mexican-authoritiesrelocate-hundreds-of-migrants-from-border-city11550262962 (date of access: 01.03.2021).

Morain D. There's a Front-Runner for Kamala Harris's Senate Seat - But Gavin Newsom Could Surprise Us All Opinion. 2020. URL: https://www. washingtonpost.com/opinions/2020/11/23/ gavin-newsom-replace-kamala-harris-senateseat/ (date of access: 01.03.2021).

Petaling J. No Element of Racism in SOPs, Says Ismail Sabri. 2020. URL: https://www.thesundaily.my/ home/no-element-of-racism-in-sops-says-ismailsabri-AJ5139828 (date of access: 01.03.2021).

Powell J. The 20 Photographs of the Week. 2018. URL: https://www.theguardian.com/artanddesign/ gallery/2018/jun/23/the-20-photographs-of-theweek (date of access: 01.03.2021).

Shear M. D. Transition Highlights: Biden Plans to Name Blinken, Sullivan and Thomas-Greenfield to Cabinet. 2020. URL: https://www.nytimes.com/ live/2020/11/22/us/joe-biden-trump (date of access: 01.03.2021).

\section{REFERENCES}

Akhmanova O.S., 1966. Slovar lingvisticheskikh terminov [Dictionary of Linguistic Terms]. Moscow, Sovetskaya Etsiklopediya Publ. 606 p.

Dejk T.A. van, 2015. Diskurs $i$ vlast': reprezentaciya dominirovaniya $v$ yazyke $i$ kommunikacii [Discourse and Power: Representing Dominance in Language and Communication]. Moscow, URSS Publ., LIBROKOM Publ. 352 p.

Baker P., 2006. Using Corpora in Discourse Analysis. London, Bloomsbury Academic. 198 p.

Baker P., Gabrielatos C., McEnery T., 2013. Discourse Analysis and Media Attitudes: The Representation of Islam in the British Press. Cambridge, Cambridge University Press. 280 p.

Baker P., KhosraviNik M., Krzyzanowski M., McEneryT., Wodak R., 2008. A Useful Methodological
Synergy? Combining Critical Discourse Analysis and Corpus Linguistics to Examine Discourses of Refugees and Asylum Seekers in the UK Press. Discourse \& Society, vol. 19 (3), pp. 273-306. DOI: https://doi.org/10.1177/0957926508088962.

Blinder S., 2015. Imagined Immigration: The Impact of Different Meanings of 'Immigrants' in Public Opinion and Policy Debates in Britain. Political Studies, vol. 63 (1), pp. 80-100.

Hunston S., 2007. Semantic Prosody Revisited. International Journal of Corpus Linguistics, vol. 12 (2), pp. 249-268.

Gabrielatos C., Baker P., 2006. Representation of Refugees and Asylum Seekers in UK Newspapers: Towards a Corpus-Based Comparison of the Stance of Tabloids and Broadsheets. First International Conference: Critical Approaches to Discourse Analysis Across Disciplines (University of East Anglia, Norwich, UK, 2930 June 2006). URL: https://eprints.lancs.ac.uk/ id/eprint/250 (accessed 1 March 2021).

Gabrielatos C., Baker P., 2008. Fleeing, Sneaking, Flooding. A Corpus Analysis of Discursive Constructions of Refugees and Asylum Seekers in the UK Press, 1996-2005. Journal of English Linguistics, vol. 36 (1), pp. 5-38. DOI: https:// doi.org/10.1177/0075424207311247.

KhosraviNik M., 2009. The Representation of Refugees, Asylum Seekers and Immigrants in British News-Papers During the Balkan Conflict (1999) and the British General Election (2005). Discourse \& Society, vol. 20 (4), pp. 477-498. DOI: https://doi.org/10.1177/0957926509104024.

McEnery T., Hardie A., 2011. Corpus Linguistics: Method, Theory and Practice. Cambridge, Cambridge University Press. 292 p.

Philo G., Briant E., Donald P., 2013. Bad News for Refugees. London, Pluto Press. 224 p.

Sinclair J., 1991. Corpus, Concordance, Collocation. Oxford, Oxford University Press. 179 p.

Stubbs M., 1995. Collocations and Semantic Profiles: On the Cause of the Trouble with Quantitative Studies. Functions of Language, vol. 2 (1), pp. 2355. DOI: https://doi.org/10.1075/fol.2.1.03stu.

\section{SOURCES}

Borger J. Downright Dangerous: Democrats' Alarm As Trump Stacks Pentagon with Loyalists, 2020. URL: https://www.msn.com/en-gb/news/world/ downright-dangerous-democrat-alarm-astrump-stacks-pentagon-with-loyalists/arBB1aUsS2?fbclid=IwAR0BOfY8tolEcZnPO TiJK1RnBljvchQpjAzd1_4XIITI7OSS5wokP48Lno (accessed 1 March 2021). 
М.С. Матыцина, Т. Григорянова. Англоязычный дискурс иммиграции в аспекте корпусной лингвистики

Burchfield R.W. The New Fowler's Modern English Usage. Oxford, Clarendon Press, 1996. 864 p.

Corpus of News on the Web (NOW). URL: https:// www.english-corpora.org/now/.

Leonhardt D. Team Trump's 3 Bizarre Defenses of Child Separations, 2018. URL: https:// www.nytimes.com/2018/06/18/opinion/trumpfamily-separation-immigrant-border.html (accessed 1 March 2021).

Montes J. Mexican Authorities Relocate Hundreds of Migrants from Border City, 2019. URL: https://www.wsj.com/articles/mexicanauthorities-relocate-hundreds-of-migrantsfrom-border-city-11550262962 (accessed 1 March 2021).

Morain D. There's a Front-Runner for Kamala Harris's Senate Seat - But Gavin Newsom Could
Surprise Us All Opinion, 2020. URL: https:// www.washingtonpost.com/opinions/2020/11/ 23/gavin-newsom-replace-kamala-harris-senateseat (accessed 1 March 2021).

Petaling J. No Element of Racism in SOPs, Says Ismail Sabri, 2020. URL: https:/www.thesundaily.my/ home/no-element-of-racism-in-sops-saysismail-sabri-AJ5139828 (accessed 1 March 2021).

Powell J. The 20 Photographs of the Week, 2018. URL: https://www.theguardian.com/artanddesign/ gallery/2018/jun/23/the-20-photographs-of-theweek (accessed 1 March 2021).

Shear M.D. Transition Highlights: Biden Plans to Name Blinken, Sullivan and Thomas-Greenfield to Cabinet, 2020. URL: https://www.nytimes. com/live/2020/11/22/us/joe-biden-trump (accessed 1 March 2021).

\section{Information About the Authors}

Marina S. Matytcina, Doctor of Sciences (Philology), Professor, Department of Foreign Languages, Lipetsk State Technical University, Moskovskaya St, 30, 398055 Lipetsk, Russia, lipmarina@gmail.com, https://orcid.org/0000-0001-6102-4397

Tatiana Grigoryanova, Candidate of Sciences (Philology), Associate Professor, Department of Romance and Slavic Languages, University of Economics in Bratislava, 85235 Bratislava, Slovakia, tatiana.grigorjanova@gmail.com, https://orcid.org/0000-0002-3569-7130

\section{Информация об авторах}

Марина Станиславовна Матыцина, доктор филологических наук, профессор кафедры иностранных языков, Липецкий государственный технический университет, ул. Московская, 30, 398055 г. Липецк, Россия, lipmarina@gmail.com, https://orcid.org/0000-0001-6102-4397

Татьяна Григорянова, кандидат филологических наук, доцент кафедры романских и славянских языков, Экономический университет в Братиславе, 85235 г. Братислава, Словакия, tatiana.grigorjanova@gmail.com, https://orcid.org/0000-0002-3569-7130 